\title{
La relación entre las políticas de inversión extranjera en Colombia y los acuerdos internacionales de inversión*
}

Fecha de recepción: 5 de febrero de 2018

Fecha de aceptación: 12 de julio de 2018

Doi: dx.doi.org/10.12804/revistas.urosario.edu.co/acdi/a.7569

\section{Laura Victoria García Matamoros ${ }^{* *}$}

Resumen: el artículo introduce algunas reflexiones sobre las implicaciones de los acuerdos de protección y promoción de las inversiones (APPI) y de los capítulos de inversión en los tratados de libre comercio (TLC) para países del nivel de desarrollo de Colombia, y, en consecuencia, de la importancia de contar con políticas claras en materia de inversión extranjera y con un modelo robusto de medición de beneficios en términos de desarrollo y de riesgos en cuanto a la limitación a su capacidad regulatoria y su eventual responsabilidad internacional por el incumplimiento de las obligaciones adquiridas mediante estos acuerdos. Para ello refiere el escrito algunos estándares de protección particularmente sensibles y, a partir de allí, aporta un estudio de la evolución de la política interna de inversión colombiana,

* Este artículo ha sido elaborado con la colaboración de Andrea Móseres Fernández, Juan Sebastián Pereira Rico y Juan Manuel Montoya Quintero, asistentes de investigación. ** Abogada de la Universidad del Rosario, posgrado en Derecho Internacional Privado de la Universidad de París II, doctora en Derecho de la Universidad Externado de Colombia. Profesora titular de carrera académica de la Facultad de Jurisprudencia de la Universidad del Rosario, directora del Grupo de Investigación en Derecho Internacional y codirectora de la Especialización en Derecho Internacional de los Derechos Humanos y DIH de la misma universidad.

Para citar este artículo: García Matamoros, L. V., "La relación entre las políticas de inversión extranjera en Colombia y los acuerdos internacionales de inversión”, Anuario Colombiano de Derecho Internacional (ACDI), 2019, 12, pp. 85-120. Doi: dx.doi.org/10.12804/revistas.urosario.edu.co/acdi/a.7569 
segmentada por los períodos gubernamentales, partiendo de lo incluido en los planes nacionales de desarrollo y en los documentos Conpes, así como en modelos de tratados diseñados en los distintos gobiernos, en aras de identificar si Colombia, en lo que llevamos de este siglo, ha contado con políticas estructuradas que orienten los procesos de negociación y conclusión de tratados que correspondan a los modelos propuestos y a los intereses del Estado. Lo anterior justificado en que Colombia en los últimos dos años se ha visto expuesta a importantes disputas en materia de inversión extranjera, varias de las cuales ya se encuentran materializadas en procesos ante el CIADI.

Palabras clave: inversión extranjera, acuerdos de protección y promoción de las inversiones, políticas públicas de inversión extranjera, modelos de acuerdos bilaterales de inversión, capacidad regulatoria.

The Relationship between Foreign Investment Policies in Colombia and the International Investment Agreements

Abstract: The paper reflects on the implications of the foreign investment protection and promotion agreements (FIPA) and the investment chapters of the free trade agreements (FTA) for countries with a level of development similar to that of Colombia and, consequently, on the importance of establishing clear policies on foreign investment and a robust model to measure the benefits for the country's development but also the risks in terms of regulatory capacity and international liability for non-compliance with the obligations acquired through these agreements. For this purpose, the paper refers to some particularly sensitive protection standards and, from there, analyses the evolution of Colombia's internal investment policy during different government periods based on the relevant provisions of the national development plans, the documents of the National Council for Economic and Social Policy (NCESP) and the model treaties drafted by different governments. This analysis seeks to identify whether Colombia has, so far in this century, established thorough policies for the negotiation and conclusion of investment treaties, and whether the concluded treaties correspond to the proposed models and protect the interests of the State. The study is justified by the increase of significant investment 
disputes against Colombia in the last two years, several of which are already materialized in procedures before the ICSID.

Key words: Foreign investment, foreign investment protection and promotion agreements, public policies for foreign investment, models of bilateral investment treaties, regulatory capacity.

A relação entre as políticas de investimento estrangeiro na Colômbia e os acordos internacionais de investimento

Resumo: o artigo introduz algumas reflexões sobre as implicações dos Acordos de Proteção e Promoção dos Investimentos (APPI) e dos capítulos de investimento nos Tratados de Livre Comércio (TLC) para países do nível de desenvolvimento da Colômbia e em consequência, da importância de contar cm políticas claras em matéria de investimento estrangeiro e com um modelo robusto de medição de benefícios em termos de desenvolvimento e de riscos em quanto à limitação à sua capacidade regulatória e de sua eventual responsabilidade internacional pelo incumprimento das obrigações adquiridas mediante estes acordos. Para isto, refere o escrito, alguns standards de proteção particularmente sensíveis e, a partir dali, aporta um estudo da evolução da política interna de investimento colombiano, segmentada pelos períodos governamentais, partindo do incluído nos Planos Nacionais de Desenvolvimento e nos Documentos CONPES, assim como em modelos de tratados desenhados nos diferentes governos, em favor de identificar se a Colômbia, no que tem corrido deste século, tem contado com políticas estruturadas que orientem os processos de negociação e conclusão de tratados que correspondam aos modelos propostos e aos e aos interesses do Estado. O anterior justificado em que a Colômbia nos últimos dois anos se tem visto exposta a importantes disputas em matéria de investimento estrangeiro, varias das quais já se encontram materializadas em processos ante o CIADI.

Palavras-chave: investimento estrangeiro, acordos de proteção e promoção dos investimentos, políticas públicas de investimento estrangeiro, modelos de acordos bilaterais de investimento, capacidade regulatória. 


\section{Introducción}

La inversión extranjera ha sido presentada en Colombia y en el mundo como un elemento fundamental para el desarrollo económico de los países. En esa misma línea y a pesar de que no existen cifras contundentes al respecto, ${ }^{1}$ se afirma que la suscripción de acuerdos de protección y promoción de las inversiones (APPI o BIT — por su sigla en inglés-) y tratados de libre comercio (TLC) con capítulos de inversiones son una forma de atraer inversión extranjera y de esta manera obtener beneficios como la creación de empleo, la transferencia de nueva tecnología y capacitación hacia su territorio, el fortalecimiento de las conexiones con el Estado de origen de la inversión y los mercados internacionales, el robustecimiento de la industria nacional y mayores ingresos por concepto de los impuestos recaudados de los inversionistas. ${ }^{2}$

No obstante la mirada positiva de la inversión, es necesario observar cómo los acuerdos de protección de las inversiones vienen siendo cuestionados, en la medida en que varios países en desarrollo han tenido que enfrentar millonarias demandas ante instancias internacionales. Actualmente, Latinoamérica tiene el segundo lugar como región con más demandas ante el CIADI. ${ }^{3}$ Así mismo, la recepción de casos de la región ante el CIADI se ha incrementado de manera importante si se tiene en cuenta que hasta junio de 2017 se tenían 53 casos registrados, y solo en un año, es decir, hasta junio de 2018, el CIADI ya registró 26 nuevos casos. ${ }^{4}$ Es como consecuencia de dichas demandas y numerosas condenas cuantiosas que varios países se han retirado del CIADI, entre estos Argentina, o han denunciado los acuerdos internacionales suscritos, entre estos Ecuador, que en 2017

1 Yackee, J., "Bilateral investment treaties, credible commitment, and the rule of (international) law: do BITs promote foreign direct investment?", Law \& Society Review, 2008, 42, (4), p. 806. Yackee cita una serie de estudios: algunos dicen que la firma de TBI lleva a mayor inversión extranjera directa, otros dicen que podrían incluso reducirla. En todo caso ninguno es concluyente.

2 Salacuse, J. W., The law of investment treaties, Oxford University Press, Nueva York, 2010, p. 38.

3 Con un $23 \%$ de las demandas de Latinoamérica justo detrás de Europa. ICSID Statistics 2018-II, en https://icsid.worldbank.org/en/Documents/resources/ICSID $\% 20$ Web $\% 20$ Stats $\% 202018-2 \% 20$ (English).pdf

4 Para un total de 676 casos registrados ante el CIADI. Ibid. 
denunció doce de sus TBI. ${ }^{5}$ Chile, por su parte, anunció la renegociación de los TBI y el establecimiento de un nuevo modelo de acuerdo. Pero dicha reacción también se puede ver, por ejemplo, con el gobierno sudafricano, que decidió no renovar y denunciar una serie de TBI, ${ }^{6}$ alegando de esta forma una posibilidad de estructurar la política pública en materia de inversión.

En este contexto es necesario observar que Colombia en las últimas tres décadas ha venido suscribiendo diferentes APPI y TLC, en la medida en que desde la década de los noventa y en consonancia con las políticas liberales de la época, el país dio un giro a su modelo económico, al pasar de una lógica proteccionista y de mercado cerrado a una donde se alentaba la inversión extranjera y la inclusión de la economía nacional en canales comerciales y financieros mundiales. ${ }^{7}$ Tal necesidad de ingresar a nuevos mecanismos que alentaran la economía y el intercambio comercial de bienes y servicios colombianos en el exterior ha tenido como consecuencia una reforma constitucional ${ }^{8}$ y la entrada en vigor de 16 acuerdos internacionales de inversión (AII); dentro de estos se han suscrito nueve tratados de libre comercio con sus respectivos capítulos de inversión (México, Chile, Triángulo del Norte, ALELC, Canadá, Estados Unidos, Unión Europea, Corea del Sur y Costa Rica) y siete acuerdos para la promoción y protección recíproca de las inversiones (APPI) (España, Suiza, Perú, China, India, Reino Unido y Japón). ${ }^{9}$

5 Ibid., Italia (2001), Bolivia (1995), Perú (1999), España (1996), Estados Unidos (1993) y Canadá (1996). Así mismo, con Argentina (1994), Venezuela (1993), Francia (1994), Países Bajos (1999), Suecia (2001), Chile (1993), Suiza (1968), China (1994), Alemania (1996) y Gran Bretaña e Irlanda del Norte (1994).

6 Schlemmer, Engela C., "An overview of South Africa's bilateral investment treaties and investment policy”, ICSID Review - Foreign Investment Law Journal, 2016, 31, (1), pp. 167-193.

7 Méndez, C. F., "Tratamiento de la inversión extranjera en Colombia”, en García Matamoros, L. \& Aljure Salame, A. C., Estudios contemporáneos de derecho internacional privado, Universidad del Rosario-Legis, Bogotá, 2016; Moyano Buitrago, M. L. \& Gil León, J. M., "Efectos de la inversión extranjera directa sobre el crecimiento económico en Colombia: evidencia empírica 2000-2010”, 2015, p. 10.

8 El Acto Legislativo 1 de 1999 modificó el artículo 58 de la Constitución Política, eliminando la posibilidad de decretar expropiaciones sin indemnización, por ser contrario a lo establecido en los APPI. Al respecto ver Linares Cantillo, Alejandro, "La reforma al artículo 58 de la Carta. Internacionalizar la protección: una forma de estimular la inversión extranjera", Ámbito Jurídico, 2000, 2, (8).

9 Mincomercio, "Acuerdos internacionales vigentes", en http://www.tlc.gov.co/loader. php?IServicio $=$ Publicaciones\&id $=11963$ 
Ahora bien, teniendo en cuenta la importancia de tales instrumentos, la lógica económica, política y jurídica de los Estados exige que estos sean suscritos atendiendo a los intereses de los países en juego, lo cual significa la necesidad de contar con políticas internas, que, partiendo de una identificación de necesidades y de sectores que requiere fortalecer, defina las condiciones en las que se requiere que entre la inversión extranjera, tanto en cuanto a la protección que está dispuesta a dar a cambio de beneficios para su desarrollo (lo cual se hace a partir de la construcción propia de un modelo de APPI $)^{10}$ como a las industrias, empresas o servicios que pretende desarrollar o que pretende restringir frente a esta inversión (lo cual se hace a partir de un análisis de la economía del país que permita proponer políticas públicas).

Experiencias cercanas que vale la pena resaltar son las de Ecuador y Bolivia, que han venido trabajando en la materia a nivel constitucional, legal, reglamentario y de políticas públicas, buscando establecer un sistema equilibrado en función de sus intereses. Así, solo por citar algunos ejemplos, Ecuador, a pesar de haber emprendido el proceso de denuncias antes enunciado, ha planteado la necesidad de establecer un sistema jurídico para dar a los inversores las garantías suficientes, pero sin abandonar la previsión de reglas claras y transparentes de carácter interno, de manera que, por ejemplo, con la expedición del Código de la Producción se buscó equiparar las condiciones previstas en la redacción típica de un acuerdo bilateral de protección y promoción recíproca de inversiones con los intereses del Estado, ${ }^{11}$ y ha venido construyendo su régimen de inversiones con base en el Plan Nacional del Buen Vivir, de manera que se propone un proyecto o modelo de acuerdo de comercio para el desarrollo (ACD). ${ }^{12}$

10 Illescas, J., "Los tratados de protección de inversiones y su utilidad para los inversores españoles en Latinoamérica", Actualidad Jurídica Uría \& Menénder, (5), pp. 83-93. La estructura base de los modelos APPI proviene de 1959 y 1967 por un grupo de estudio privado y la OCDE. Sin embargo, algunos Estados, como el colombiano y el estadounidense, se sirven de modelos actualizados periódicamente, que reflejan las políticas internas de los Estados. Vandevelde, K., "The Bilateral Investment Treaty Program of the United States", Cornell International Law Journal, 1988, 21, pp. 201-276.

11 Guerra Bello, Gustavo, "La propuesta de modelo de acuerdo de comercio para el desarrollo del gobierno de Ecuador en materia de inversiones y comercio transfronterizo de servicios: límites y dilemas", Universidad Andina Simón Bolívar, sede Ecuador, informe de investigación, Quito, 2012, p. 30, en http://repositorio.uasb.edu.ec/bitstream/10644/4063/1/PI-2012-13-Guerra-La\%20propuesta.pdf

12 Ibid., pp. 24 y ss. 
Por su parte, Bolivia, también inmerso en el proceso de denuncia de los APPI ratificados, además de estar trabajando en su propio modelo de acuerdo de inversión, ha decidido regular el tema mediante normas internas, ${ }^{13}$ que, si bien no excluyen la posibilidad de negociar, suscribir y ratificar este tipo de acuerdos, sí establecen principios y reglas que permiten la inversión extranjera y su protección racionalizada en términos de sectores restringidos para la inversión extranjera o priorizados a favor de la inversión nacional, particular pero no exclusivamente en cuanto a recursos naturales, el no reconocimiento de jurisdicciones internacionales y el trato nacional con limitaciones, entre otros. ${ }^{14}$

Al lado de estos casos encontramos también experiencias de países como Brasil, que no ha suscrito este tipo de acuerdos sino con un número reducido de Estados y sin aceptación de la jurisdicción internacional; ${ }^{15} \mathrm{O}$ Sudáfrica, que, consciente de la importancia de sus recursos naturales y su desigualdad social, ha emprendido también un proceso de revaluación de los tratados de inversión suscritos. ${ }^{16}$

Sin duda, una de las principales preocupaciones que generan los tratados de inversión radica en que los estándares de protección de común inclusión en los acuerdos y alegados frecuentemente ante las instancias internacionales por parte de los inversionistas son amplios y ambiguos, de manera que su eventual aplicación en últimas termina afectando la capacidad regulatoria del Estado, el cual, en ocasiones, se encuentra en la encrucijada de aplicar medidas necesarias en el ámbito interno, pero con consecuencias negativas en el ámbito internacional, por una posible afectación de los intereses de los inversionistas extranjeros.

Así entonces, las protecciones sustantivas que Colombia ha incluido en los instrumentos de inversión representan un tema sensible para el Estado y su capacidad regulatoria, toda vez que sus actuaciones,

13 República de Bolivia, Constitución Política, Ley de Promoción de Inversiones, Ley de Conciliación y Arbitraje.

14 República de Bolivia, Constitución Política, art. 320.

15 Mozambique, Malawi, Angola y México. Ver Bernasconi-Osterwalder, Natalie \& Dietrich Brauch, Martín, "Comparative commentary to Brazil's cooperation and investment facilitation agreements (CIFAs) with Mozambique, Angola, Mexico, and Malawi”, en https:// www.iisd.org/library/comparative-commentary-brazil-cooperation-and-investment-facilitation-agreements-cifas

16 Schlemmer, op. cit. 
aunque tendientes a la satisfacción del interés general, pueden traducirse en violaciones a las obligaciones que subyacen a un acuerdo de inversión. De manera que las reclamaciones suelen ampararse en interpretaciones extensivas de los estándares de protección que a continuación se abordan, los cuales, si bien no son los únicos, los referimos por ser aquellos que con mucha frecuencia se alegan y se debaten en las instancias internacionales.

\section{a) Cláusula paraguas}

En términos generales, la cláusula paraguas se concibe como aquella que "permite elevar al nivel de conflicto de raigambre internacional el surgido con relación a un contrato entre un inversionista y el Estado receptor". ${ }^{17}$ Dicho de otro modo, bajo la égida de la cláusula paraguas, un inversionista extranjero puede activar el mecanismo de solución de controversias previsto en el acuerdo de inversión cuandoquiera que se ignoren las obligaciones de un contrato celebrado entre aquel y el Estado receptor, en la medida en que dicha violación comporta el desconocimiento del tratado sobre el que se funda. Luego, la obligación que subyace al contrato tiene la virtualidad de convertirse en obligación de derecho internacional para el Estado, cuestión esta que revela la complejidad de delimitar el alcance de la cláusula. Valga aclarar que la cláusula paraguas es de carácter residual, esto es, se invoca cuando las actuaciones desplegadas por el Estado no son constitutivas de una expropiación indirecta o un trato discriminatorio. ${ }^{18}$

La sensibilidad que se predica de esta cláusula estriba en la ausencia de homogeneidad en la interpretación sobre su alcance, tanto así que en la actualidad permanece sin una definición unívoca en la jurisprudencia arbitral. Al respecto, la discusión ha sido abordada, entre otros, en el asunto El Paso Energy c. Argentina, en donde el tribunal aseguró que una cláusula paraguas no podía transformar cualquier reclamo contractual en un reclamo basado en un tratado, bajo el entendido de que si así fuere todos los compromisos asumidos por el Estado receptor sobre las inversiones,

17 Gamboa Morales, Nicolás, "Algunas consideraciones sobre antecedentes y evaluación arbitral de la cláusula paraguas", Revista Brasileira de Arbitragem, 2009, 5, (22), pp. 116-129. 18 Sommer, Christian, "La aplicación de estándares de protección de inversiones extranjeras. Una mirada desde los casos argentinos", Anuario Colombiano de Derecho Internacional, 2014, pp. 95-130. 
aunque de escasa entidad, constituirían reclamos sobre el tratado mismo. ${ }^{19}$ La dicotomía entre la interpretación restringida y amplia de la cláusula paraguas, como se ha evidenciado en los asuntos SGS c. Pakistán y SGS c. Filipinas, respectivamente, da cuenta de la intensidad del debate — no solo académico- que pretende dilucidar su alcance y limitación. Esa falta de certeza sugiere para el Estado en desarrollo reflexionar sobre la pertinencia o no de incluir cláusulas de esa estirpe, so pena de tener que enfrentar reclamos en sede arbitral con ocasión a incumplimientos que puedan no tener la entidad tal de entrañar la violación de un acuerdo de inversión.

\section{b) Trato justo y equitativo}

Este estándar, de variada interpretación y alcance, es generalmente incorporado en los acuerdos internacionales de inversión, en tanto su alcance puede comprender las garantías del debido proceso, la buena fe, transparencia, protección de las inversiones y las expectativas legítimas del inversionista. Dado su carácter subjetivo, la significación del estándar - cuandoquiera que el instrumento de inversión se resienta en su claridad-, tanto como su entendimiento y aplicación, se determina caso a caso. De ahí que sea una de las cláusulas cuya inclusión termina por interferir en el poder regulatorio del Estado, toda vez que la ambigüedad del lenguaje con el que se suele consagrar conduce a interpretaciones volubles, al punto de enmarcar cualquier actuación del Estado en una presunta violación al trato justo y equitativo.

Como lo sostienen Márquez Escobar y Villegas Carrasquilla (2009), el significado de lo "justo y equitativo" se vierte en cuatro interpretaciones distintas, a saber: i) el significado plano del término, en su sentido natural y obvio, esto es, que el inversor tiene certeza de que el trato de su inversión se desarrollará bajo el más simple de los sentidos de equidad y justicia; ii) el alcance de esta protección sustancial se determina en relación con el estándar internacional mínimo; iii) el contenido del estándar se acrisola solo en relación con otros estándares, como lo son el trato nacional y la protección y seguridad plena; y iv) la interpretación según la cual el estándar

19 Castro Peña, M. N., "El Estado colombiano ante un arbitraje internacional de inversión”, Derecho del Estado, 2017, (38), pp. 23-66. 
se construye a partir de la conjunción 'y', que determina un tratamiento más que solo justo y más que solo equitativo. ${ }^{20}$

Como se anticipó, la sensibilidad que supone la inclusión de este estándar para los Estados receptores de inversión estriba en las interpretaciones disímiles que los tribunales le han conferido. Así, en casos como el de Waste Management c. México, ${ }^{21}$ el CIADI ha provisto el contenido del estándar a la luz del principio de transparencia; por su parte, en el asunto Técnicas Medioambientales Tecmed c. México, ${ }^{22}$ se ha interpretado el estándar bajo el principio de buena fe, de conformidad con lo preceptuado en la Convención de Viena sobre Derecho de los Tratados. También se ha asociado el estándar a la prohibición de denegación de justicia y los tratos arbitrarios, y a la protección de las legítimas expectativas del inversionista.

En aras de evidenciar la amplitud del estándar, se traerá a colación el artículo 805 del Acuerdo de Promoción Comercial suscrito entre Colombia y Canadá. El inciso segundo de esa disposición indica que el concepto de "trato justo y equitativo" no requiere un trato adicional o más allá de aquel exigido por el nivel mínimo de trato de extranjeros del derecho internacional consuetudinario, entendido este como la costumbre - en tanto práctica generalmente aceptada como ley, de conformidad con el artículo 38 del Estatuto de la Corte Internacional de Justicia-. Aunque el alcance del concepto se supedita, en principio, a la redacción de la cláusula, la interpretación literal de aquella no disipa la duda sobre su aplicación. Esa dificultad es la que Colombia no solo deberá prevenir, sino enfrentar por las demandas que cursan en la actualidad, entre ellas, la de Eco Oro Minerals Corp., ${ }^{23}$ que, bajo el amparo del TLC con Canadá, estimó conculcado el estándar de que trata el 805 del instrumento de inversión como consecuencia de la delimitación que cercenó los derechos mineros en las zonas de páramo.

\footnotetext{
20 Márquez Escobar, Pablo \& Villegas, Lorenzo, "Regulación e inversión extranjera: los tratados de promoción recíproca de inversiones y el estándar de trato justo y equitativo", Revista Colombiana de Derecho Internacional, 2009, pp. 155-180.

21 Waste Management, Inc. v. United Mexican States (Number 2), ICSID Case ARB(AF)/00/3.

22 Técnicas Medioambientales Tecmed, S.A. v. The United Mexican States, ICsid Case ARB $(\mathrm{AF}) / 00 / 2$.

23 Eco Oro Minerals Corp. v. Republic of Colombia, ICSID Case ARB/16/41.
} 


\section{c) Prohibición de expropiación sin compensación}

Es indudable que el derecho internacional de las inversiones protege el derecho de propiedad del extranjero. Aunque no es común en la actualidad que haya una transferencia formal de la propiedad por parte del Estado, constituyendo con ello una expropiación directa, sí lo es que, en ejercicio de su poder soberano, el Estado receptor interfiera en el derecho de uso de la propiedad e intereses del inversionista — limitación que se refugia en la denominada expropiación indirecta- A la cláusula de prohibición de expropiación se yuxtapone la facultad del Estado para expropiar por motivos de utilidad e interés público, lo que revela la dificultad de diferenciar las medidas regulatorias desplegadas por el Estado en procura de la protección de este interés y aquellas actuaciones que representen una injerencia ilegítima en los derechos del inversionista. ${ }^{24}$

La consagración de cláusulas de prohibición de expropiación tienden a mitigar la inseguridad y el riesgo que asume el inversionista por las actuaciones del Estado, por lo que generalmente se acompañan de la obligación, en cabeza de este último, de indemnizar al inversionista que ha visto reducida su inversión. Aunque la costumbre internacional no reconoce el pago de compensaciones por una expropiación que se fundamente en el ejercicio del poder de policía o utilidad pública, no es menos cierto que la tendencia es que los acuerdos contemplen el pago compensatorio en todos los casos de expropiación de una inversión extranjera, además de otras condiciones que han de concurrir para su realización, cuales son la utilidad pública, la no discriminación y el respeto al debido proceso. ${ }^{25}$

La sensibilidad de esta cláusula responde al alcance del concepto de expropiación indirecta o regulatoria que se define a partir de las circunstancias de cada caso. $\mathrm{Al}$ respecto, se ha sostenido ${ }^{26}$ que corresponde al tribunal estudiar tres aspectos: i) la acción gubernamental, ii) la medida con la que el gobierno interfiere en las legítimas expectativas de la inversión y iii) el impacto económico de la medida gubernamental. Sobre el particular,

\footnotetext{
24 Páez, Marisol, "La expropiación indirecta frente al CIADI: consideraciones para la autorregulación de los actos administrativos del Estado", Revista de Estudios Internacionales, 2006, 39, (153).

25 Ibid., p. 9.

26 Castro Peña, op. cit., pp. 47-48.
} 
se ha de soslayar el imaginario según el cual toda medida o actuación del Estado tiene la virtualidad de constituir una expropiación indirecta. Si así fuere, esto es que toda afectación — por mínima que sea— al valor de la inversión constituye una expropiación, el ejercicio del poder regulatorio del Estado se tornaría inane y, de suyo, entrañaría la inmovilidad y parálisis frente a la garantía del interés general, que terminaría supeditándose a los intereses particulares del inversionista.

En suma, es unánime la consideración según la cual el derecho de las inversiones ha de garantizar y proteger la propiedad del inversionista, tanto como los beneficios que subyacen a su actividad. Sin embargo, no es unívoco el alcance que se predica de la expropiación indirecta, bajo el entendido de que hay actuaciones del Estado que oscilan entre la interferencia ilegítima en los derechos del inversionista y las medidas regulatorias amparadas por los instrumentos nacionales e internacionales y las necesidades urgentes del Estado en términos sociales, políticos o económicos. Así mismo, los pronunciamientos arbitrales han sido disímiles, adoptando algunos posturas restrictivas que reducen el ámbito de la expropiación a la privación de los beneficios y propiedad del inversionista, mientras que otros arbitrajes han favorecido la interpretación amplia en la que incluyen cualquier interferencia del Estado como una expropiación. Adicionalmente, el entendimiento sobre las circunstancias que dan lugar al pago de indemnización, y aquellas que no, también ha sido discrepante. $\mathrm{Al}$ respecto, son dos las tendencias que revelan la ausencia de un criterio uniforme: aquella según la cual las medidas desplegadas por el Estado se justifican por el objetivo que persiguen (reconociendo con ello el derecho a proteger asuntos como la salud y el medio ambiente sin que haya lugar a indemnización); y aquella con arreglo a la cual se atiende únicamente al efecto que la medida cause en los intereses del inversionista, es decir, basta con probar la existencia del perjuicio para reconocer el pago de la indemnización. ${ }^{27}$

Aunque el abordaje de aquellas cláusulas que se consideran sensibles para los Estados en desarrollo se redujo a las tres indicadas, por ser aquellas más alegadas por los inversionistas en sus demandas, también es cierto que estándares como el de trato nacional y las formas de solución de controversias que permiten al inversionista acudir directamente a instancias

27 Páez, op. cit., pp. 30-34. 
internacionales para reclamar contra el Estado receptor de la inversión suponen una limitación implícita al poder regulatorio del Estado que puede ser mitigada con la previsión de disposiciones claras, limitantes y precisas, pero, sobre todo, pactadas entendiendo su alcance y los riesgos que representan para el Estado. Así, los acuerdos de inversión que se diseñen - para el caso colombiano, como lo confirma el más reciente modelo de 2017 — han de anticipar cláusulas que se armonicen con el ordenamiento interno y que reconozcan expresamente la indiscutible conservación del poder soberano del Estado para regular asuntos de interés público.

Bajo este contexto, en las líneas que siguen se presenta un estudio del proceso de suscripción de tratados de inversión, de manera que se analiza la evolución de la política interna de inversión colombiana, segmentada por los períodos gubernamentales, partiendo de lo incluido en los planes nacionales de desarrollo y en los documentos Conpes, así como en modelos de negociación, en aras de identificar si Colombia, en lo que llevamos de este siglo, ha contado con políticas estructuradas que orienten los procesos de negociación y conclusión de tratados que correspondan a los modelos propuestos y a los intereses del Estado, más aún teniendo en cuenta que en los últimos dos años el país se ha visto expuesto ante importantes disputas en materia de inversión extranjera, varias de las cuales ya se encuentran materializadas en procesos ante el CIADI.

\section{Evolución de la política en materia de inversión extranjera en Colombia 2002-2017}

Con el propósito de evaluar la política interna que se ha construido en materia de inversión extranjera directa (IED), es necesario entender el marco normativo en el que esta se ha desarrollado. Es relevante comenzar por señalar que los artículos 150, 371 y 372 de la Constitución Política definen las competencias para regular los aspectos propios del régimen de cambios internacionales, las inversiones, los aranceles y demás, con base en las cuales se expidieron las leyes 9 de 1991 y 31 de 1992, en las que se establece la definición del régimen general de inversiones. A partir de estas facultades el gobierno ha estructurado su política interna de inversiones por medio de la expedición de distintos decretos. ${ }^{28}$

\footnotetext{
28 Con base en las funciones señaladas por el Congreso, el gobierno nacional expidió el Régimen General de Inversión de Capital del Exterior en Colombia y de Capital Colombiano
} 
Adicionalmente, se debe resaltar que en materia de inversión existen dos órganos del Estado que se encargan de estructurar y regular la inversión extranjera. En primer lugar, encontramos el Consejo Nacional de Política Económica y Social (Conpes), que a partir de la expedición de documentos regula la planeación económica y social del país. ${ }^{29}$ En segundo lugar, se encuentra el Ministerio de Comercio, Industria y Turismo, que formula la política de inversión extranjera, coordina las estrategias gubernamentales para incrementar la competitividad del país y es el encargado de la negociación de tratados de inversión internacional. ${ }^{30}$ Se encuentra, adicionalmente, el Consejo Superior de Comercio Exterior como organismo asesor del gobierno nacional encargado en todo aquello relacionado con comercio exterior. ${ }^{31}$ Por su parte, está el Plan Nacional de Desarrollo (PND) ${ }^{32}$ como instrumento que expresa lo que los distintos gobiernos han considerado en materia de inversión. Así, en el entendido de que se trata de lineamientos gubernamentales, el análisis de las políticas se realizará con base en los períodos presidenciales que van en lo corrido de este siglo.

\subsection{Mandato de Álvaro Uribe Vélez 2002-2010}

De acuerdo con las propuestas de campaña que le permitieron llegar a la presidencia en dos períodos consecutivos 2002-2006 y 2006-2010, el gobierno de Álvaro Uribe Vélez proclamó la importancia de la inversión extranjera directa (IED), ${ }^{33}$ postura que se encuentra reflejada en sus dos

en el Exterior, Decreto 2080 de 2000, modificado parcialmente por los decretos 1844 de 2003, 4210 de 2004 y 1866 de 2005, expedidos por el gobierno nacional; el Decreto 2466 de 2007, por el cual se modifica el Régimen General de Inversiones de Capital del Exterior en Colombia y de Capital Colombiano en el Exterior; el Decreto 1888 de 2008, por el cual se modifica el Régimen General de Inversiones de Capital del Exterior en Colombia y de Capital Colombiano en el Exterior, en http://www.mincit.gov.co/publicaciones/14832/ normatividad_sobre_inversion_extranjera

29 Creado por la Ley 19 de 1958; Ley 152 de 1994.

30 Artículo $4^{\circ}$ de la Ley 790 de 2002.

31 Decreto 2553 de 1999.

32 El Plan Nacional de Desarrollo (PND), que determina los criterios orientadores de las políticas públicas que permiten hacer realidad las vías de desarrollo propuestas por el Presidente y la posterior evaluación de lo propuesto.

33 Ley 812 de 2003, Plan Nacional de Desarrollo 2002-2006; Ley 1151 de 2007, Plan Nacional de Desarrollo 2006-2010; “Uribe, 8 años en el poder. 2002-2010”, El Tiempo, 
PND. ${ }^{34}$ En el primero, se enunció el impulso de reformas regulatorias e institucionales en los sectores mineros, de servicios públicos, transportes y telecomunicaciones, que sirvieran para atraer a la inversión extranjera como motor del desarrollo económico. ${ }^{35}$ En este orden de ideas, se desarrollarían las relaciones bilaterales y aquellas con América Latina y el Caribe, y se impulsaría el desarrollo de la integración andina en relación con la CAN, específicamente en sus aspectos económicos, políticos y sociales. Adicionalmente, se apostó a la negociación del Acuerdo de Libre Comercio para las Américas.

En su segundo mandato, 2006-2010, se mantuvo una fuerte política dirigida a la inversión extranjera, se continuó con la política de inserción internacional y de facilitación del comercio mediante la suscripción de acuerdos internacionales de comercio de última generación, ${ }^{36}$ que garantizarían que los países ofrecieran a la inversión un margen de seguridad. ${ }^{37}$ Así mismo, internamente se proclamaba el fortalecimiento de las instituciones y el ajuste de la normativa local en beneficio y aprovechamiento de los AII, por lo que se debía fortalecer la estructura de las aduanas para

en http://www.eltiempo.com/archivo/documento/MAM-4332319; Brown, Chester \& Devashish, Krishan (eds.), Commentaries on selected model investment treaties, Oxford University Press, 2013, p. 185.

34 Si bien el período de observación de este artículo se define en función de los mandatos presidenciales de este siglo, es necesario anotar como antecedente próximo el documento Conpes 3135 del 9 de octubre de 2001, que definió los "lineamientos de política para la negociaciones internacionales de acuerdos de inversión extranjera” y en el cual se establecieron "las directrices de política para las negociaciones internacionales de acuerdos de inversión extranjera, y su objetivo fue promover las inversiones extranjeras y garantizar mayor protección y estabilidad a los inversionistas foráneos en Colombia". En Linares Cantillo, Alejandro, "El derecho sustancial aplicable en el arbitraje inversionista-Estado: hacia un régimen balanceado a través de los principios generales del derecho", tesis doctoral, Universidad Externado de Colombia, 2012, p. 220.

35 Plan Nacional de Desarrollo 2002-2006, Capítulo II.7. Política comercial, p. 141, en https://colaboracion.dnp.gov.co/cdt/pnd/pnd.pdf

36 Los acuerdos de última generación son aquellos que incluyen dentro de su texto distintos elementos más allá del comercio de bienes, como son los capítulos de inversión y servicios, y contratación pública. Los acuerdos de libre comercio de última generación incluyen capítulos de promoción y protección de inversiones.

37 Plan Nacional de Desarrollo 2006-2010, tomo II, p 621, en https:/ / colaboracion.dnp. gov.co/CDT/PND/PND_Tomo_2.pdf 
facilitar el comercio y generar políticas regulatorias que fueran acordes con el entorno mundial. ${ }^{38}$

En cuanto a los documentos Conpes, en el primer período de Álvaro Uribe se emitieron cuatro documentos en IED, cuya misión era la de modificar y ajustar la normatividad referida a la inversión en portafolio y mercado bursátil. ${ }^{39}$

Así pues, en el Documento 3197 del 26 de agosto de 2002, relativo al manejo de flujos de endeudamiento en los AII, se reiteró la inclusión de los flujos de endeudamiento en la definición de inversión extranjera, cumpliendo con unos requisitos; ${ }^{40} \mathrm{y}$, adicionalmente, concluyó que las operaciones de crédito público quedarían excluidas de la definición de inversión. ${ }^{41}$

En segundo lugar, en el Documento 3221 del 21 de abril de 2003 (ajustes a la normatividad de la inversión extranjera) se flexibilizaron los requisitos de inversión extranjera en el país, determinando que la única obligación para realizar una inversión era el registro de esta ante el Banco de la República sin importar el tipo que fuera. ${ }^{42}$

En tercer lugar, el Documento 3319 del 29 de noviembre de 2004, que tenía el objetivo de autorizar la inversión de organismos multilaterales en la economía nacional, indicó que estos incursionan en los mercados de capital como medio para adelantar la labor de financiamiento de países en vía de desarrollo. Se proponía la eliminación de la obligación de constitución de fondos de capital extranjero para las organizaciones multilaterales de crédito creadas en virtud de tratados, para que estas pudieran realizar la inversión de portafolio de capital del exterior a través de una sociedad comisionista de bolsa. ${ }^{43}$

38 Ibid.

39 Documento Conpes 3197 de 2002, documento Conpes 3221 de 2003, documento Conpes 3319 de 2004, documento Conpes 3429 de 2006.

40 Documento Conpes 3197 de 2002, relativo al manejo de flujos de endeudamiento: ser flujos de endeudamiento externo, debían excluir los pagos de servicios y operaciones de endeudamiento relacionados con el comercio exterior y debían estar sujetos a las regulaciones de la junta directiva del Banco de la República. p. 2, en https://colaboracion.dnp. gov.co/CDT/Conpes/Econ\%C3\%B3micos/3197.pdf

41 Ibid.

42 Documento Conpes 3221 de 2003, ajustes a la normatividad de la inversión extranjera, en https://colaboracion.dnp.gov.co/CDT/Conpes/Econ\%C3\%B3micos/3221.pdf

43 Ibid. 
Por último, el Documento 3429 del 13 de junio de $2006^{44}$ tuvo la intención de reducir las limitaciones que se le imponían a la inversión, por tal motivo se propuso la eliminación de requisitos de permanencia que venían del Decreto 2080 de 2000, en el que se imponía la permanencia mínima de un año a las inversiones efectuadas en el país; se indicaba que esta restricción descansaba en la fuerte depreciación que había tenido el peso al inicio del siglo y que había sido preocupante, en la medida que afectaba el desempeño de sectores productivos de bienes comercializables internacionalmente; sin embargo, en 2005 el valor de la moneda se había incrementado, por lo que era posible eliminar esta medida, al presentarse nuevas entradas de capital producto de la existencia de expectativas de apreciación y valorización de las inversiones. En este sentido, el gobierno derogó el parágrafo del artículo 10 que imponía esta restricción temporal a la inversión mediante el Decreto 1940 de 2006.

Es importante resaltar que durante el mandato del presidente Uribe entraron en vigor diez acuerdos internacionales de inversión. ${ }^{45}$

Lo hasta acá expuesto resulta coherente con el balance final presentado por el mandatario, para quien uno de sus grandes logros fue hacer realidad su eslogan de la "confianza inversionista", ${ }^{46}$ la cual, como se observó, tuvo reflejo en los instrumentos de política en los cuales se consignó una aceptación plena y sin ambages de la inversión extranjera en prácticamente todos los sectores económicos y en todas sus expresiones, así como en el avance hacia nuevos acuerdos internacionales con estándares de protección plenos. ${ }^{47}$ Todo esto, presumiblemente, hacía también pensar

44 Documento 3429 del 13 de junio de 2006, modificación al régimen de inversión extranjera en Colombia, en https://colaboracion.dnp.gov.co/CDT/Conpes/ Econ $\% \mathrm{C} 3 \% \mathrm{~B} 3 \mathrm{micos} / 3429$.pdf

45 TBI España (2005), Suiza (2006), Perú (2007), China (2008), India (2009); bajo la modalidad de TLC Estados Unidos (2006), Chile (2006), Triángulo del Norte (Salvador, Guatemala, Honduras) (2007), Canadá (2008). Adicionalmente, dos tratados fueron firmados y ratificados posteriormente, el TBI con Inglaterra (2010) y con Japón (2011).

46 Al respecto afirmaba el presidente Uribe en su página oficial: "Mientras en muchos países de América Latina se mira con desdén la inversión privada, en lo que llamaríamos una época política de nuevo estatismo, Colombia estuvo firme en el propósito de darle todas las garantías al capital nacional e internacional, con exigencia de responsabilidad social". En http://www.alvarouribevelez.com.co/es/content/confianza-inversionista

47 Para una mirada crítica, ver Zerda Sarmiento, Álvaro, "Colombia: del Japón de Suramérica a la confianza inversionista. Dos estrategias para un patrón de crecimiento reprimarizante 
que Colombia, gracias a su buen comportamiento, no sería demandada ante las instancias internacionales pactadas, situación que era reservada para países que venían adoptando medidas contrarias a los estándares internacionalmente reconocidos. No obstante, y si bien no es el tema de este artículo, en el espectro interno no se avanzó de manera equilibrada en lo relativo al apoyo a la industria, a la agricultura, a los sectores económicos que serían eventualmente afectados por los tratados suscritos, ni a la coherencia de las políticas para la protección del medio ambiente y de los derechos humanos.

\subsection{Mandato de Juan Manuel Santos Calderón}

El presidente Santos mantuvo la política de inversión similar a la del gobierno Uribe. En su primer mandato (2010-2014), se determinó que se continuaría con la estrategia de negociación, implementación y administración de acuerdos internacionales bilaterales, así como con las negociaciones multilaterales que se daban en el seno de la OMC. Pretendió adicionalmente acercarse a los países pares emergentes — CIVETS (Colombia, Indonesia, Vietnam, Egipto, Turquía, Sudáfrica)—, ${ }^{48}$ acercamiento que tuvo como efecto el inicio de las negociaciones con Turquía en 2011.

Así mismo, pretendió remover barreras arancelarias y no arancelarias que enfrentan los exportadores colombianos, y la integración a cadenas internacionales de valor. Se establecieron medidas en materia de aduanas que sirviesen para alentar el comercio de bienes, buscando la reducción de cargas en los puertos de entrada del país.

De otra parte, se formuló una estrategia para proteger al Estado de controversias internacionales contenida tanto en el PND como en el único documento Conpes desarrollado en el gobierno Santos.

En este sentido, el Conpes (3684 del 19 de octubre de 2010) contenía como eje fundamental la protección del Estado ante posibles litigios internacionales en materia de inversión por incumplimiento a las obligaciones emanadas de los AII. Al respecto vale la pena observar cómo, mientras en

con iniquidad", Universidad Nacional, Facultad de Ciencias Económicas, Serie Documentos, Escuela de Economía, No 24.

48 Consejo Superior de Comercio Exterior, Sesión 89, "Agenda de negociaciones comerciales de Colombia: actualización 2011”, en http://www.mincit.gov.co/loader.php?IS ervicio $=$ Documentos\&lFuncion $=$ verPdf\&id $=52 \&$ name $=$ Agenda_negociaciones_2011. pdf\&prefijo $=$ file 
otros países en desarrollo y particularmente latinoamericanos estaba en plena ebullición la crítica al sistema internacional de solución de controversias en materia de inversiones, justamente por los riesgos que implica para la estabilidad económica y política de los países, ${ }^{49}$ Colombia apenas es este documento Conpes estableció la necesidad de crear una entidad competente encargada de coordinar la acción de las entidades involucradas en una controversia y de ejercer y orientar la defensa del Estado, así como de actuar como el único interlocutor entre este y un inversionista. ${ }^{50}$

Así, en el año 2011 se creó la Agencia Nacional de Defensa Jurídica del Estado por medio del artículo $5^{\circ}$ de la Ley 1444. La Agencia tiene como objetivo desarrollar estrategias, planes y acciones dirigidos a dar cumplimiento a las políticas de defensa jurídica del Estado. Específicamente en materia de controversias internacionales de inversión tiene entre sus labores la de coordinar o asumir las funciones de defensa del Estado colombiano. ${ }^{51}$

En su segundo mandato (2014-2018) se continuó alentando la suscripción de AII para la promoción de la IED, bajo la consideración tradicional de que estos son un motor de crecimiento económico del país. En este sentido se indicó que debía darse una internacionalización de los sectores productivos de bienes y servicios mediante el incremento de las posibilidades en el exterior para el ingreso de productos nacionales, acrecentar los ingresos de la balanza de pagos, insertar con más eficiencia la economía en cadenas globales de valor, fortalecer las zonas francas, acompañando estas intencionalidades con la revisión de política arancelaria y de un sistema de aduanas más eficiente para el apoyo del comercio internacional.

A su vez, se proclamaba la promoción del desarrollo regional sostenible, con programas e instrumentos, consecuentes con las capacidades productivas de cada región. Se debía trabajar en áreas específicas que lograran la especialización de las regiones y que estas a su vez atrajeran la IED

49 Randall, Williams, "Nothing Sacred: developing countries and the future of international investment treaties", Department of Trade and Industry, Republic of South Africa, 2009.

50 Documento Conpes 3684 del 19 de octubre de 2010, fortalecimiento de la estrategia del Estado para la prevención y atención de controversias internacionales de inversión, en http://www.nuevalegislacion.com/files/susc/cdj/conc/conpes_3684.pdf

51 En la etapa de arreglo directo, la coordinación estará en cabeza del Ministerio de Comercio, Industria y Turismo, Decreto 4085 de 2011, art. 6 ${ }^{\circ}$, en http:/ /www.secretariasenado.gov.co/senado/basedoc/decreto_4085_2011.html 
en las regiones de menor desarrollo del país, con lo que se promoverían y difundirían mejores prácticas para el ambiente de negocios, fortaleciendo el desarrollo económico.

Como se observa, los instrumentos planteados en este período apuntaban a un crecimiento económico basado en el fortalecimiento de las relaciones económicas internacionales y en el desarrollo del adecuado andamiaje interno nacional y regional, siempre en el entendido de la bondad de la inversión extranjera y bajo la premisa de que a una mayor protección del inversionista habría un mayor interés en nuestro país. No parecía consciente el Estado colombiano de los eventuales riesgos, a pesar de que internacionalmente varios aspectos eran cuestionados y varios países pares vivían en rigor de los compromisos previamente adquiridos por vía de los APPI. Al respecto, es necesario insistir en que no es propósito de este escrito evaluar la puesta en marcha o no de las políticas, ni su bondad, aspectos que requieren un análisis económico detallado, por lo que en las líneas que siguen se observará cómo en el contexto normativo propuesto se dieron las pautas para la negociación y suscripción de los acuerdos de protección de las inversiones.

\section{Los modelos de acuerdo de protección y promoción de las inversiones en Colombia}

Como se indicó en la parte introductoria, los modelos de acuerdo internacional de inversión son el punto de partida de los Estados en la dinámica de negociación de TBI o de APPI. En estos modelos se plasma la política de inversión del país y se establecen las reglas de juego que beneficiarán a los inversionistas como consecuencia de la suscripción de un instrumento de inversión. Esta estructura de negociación tiene origen en dos modelos preparados en 1959 y en 1967 por un grupo de estudio privado y la OCDE, ${ }^{52}$ que con el tiempo los Estados fueron adoptando y, a partir de la experiencia, adaptándolos a las necesidades del Estado.

La previsión de un modelo de acuerdo facilita la negociación, pues permite a los Estados tener un documento definido con la información que se quiere proyectar en el texto final del acuerdo y que los Estados partan de una base clara de negociación, con un contenido relativamente estandarizado que contiene reglas uniformes, términos y conceptos co-

52 Vandevelde, op. cit. 
nocidos que proporcionan seguridad jurídica. De otro lado, como se ha venido señalando, para los países en desarrollo como Colombia, tanto el proceso de negociación de acuerdos como el modelo de base deben no solo responder a los intereses de protección del inversionista, sino ser el reflejo de las políticas de inversión del país. Si bien los modelos no son la única forma de representar esta política de inversión, estos sí han servido como elemento de interpretación y aplicación de los acuerdos, como así lo han demostrado algunas decisiones del CIADI en las que en ciertos casos se ha remitido a estos para aclarar provisiones de los tratados. ${ }^{53}$

Colombia, como la mayoría de los Estados que utilizan esta metodología en la negociación de instrumentos de inversión, a lo largo del tiempo ha modificado su modelo moldeándolo conforme con la experiencia y con la normativa internacional. En este sentido, podemos identificar tres grandes etapas o modelos que han marcado la política de inversión colombiana al momento de celebrar y negociar APPI o TBI: i) el modelo de negociación entre 2003 y 2006, ii) seguido por el modelo entre 2009 y 2011, y iii) finalizando con la versión más reciente de los modelos de 2017.

\section{i) Modelo de negociación entre 2003 y 2006}

El primer modelo colombiano fue establecido en 2003, diseñado en forma de plantilla, que consistía en un texto de ocho hojas con cláusulas cortas, basado exclusivamente en principios generales de comercio internacional. ${ }^{54}$ En este sentido, incluía previsiones generales con mención a los principios de trato justo y equitativo, trato nacional, definición de general expropiación, pero per se no incluía una descripción de su significado o algún criterio orientador para estos. ${ }^{55}$ En cuanto a la solución de controversias, el modelo únicamente contenía una cláusula amplia que determinaba la obligación de las partes de solucionar las controversias de manera amigable. Se trataba entonces de un modelo ambiguo, que hacía vulnerable al Estado colombiano por falta de determinación en los criterios y seguridad

\footnotetext{
53 Enron Corporation and Ponderosa Assets LP c. República de Argentina, CIADI Caso ARB/01/3, decisión de jurisdicción del 13 de enero de 2004, pár. 46; El Paso Energy International Company c. República de Argentina, CIADI Caso ARB/03/15, decisión de jurisdicción del 17 de abril de 2006, pár. 80 .

54 https://www.oecd.org/investment/internationalinvestmentagreements/WP-2004_1. pdf

55 Rivas, J. A., "Colombia”, en Brown \& Devashish, op. cit., p. 194.
} 
jurídica al momento de enfrentarse alguna controversia, y que reflejaba la inexperiencia del Estado en la negociación estructurada de este tipo de acuerdos. Este modelo sirvió como base para el TBI firmado con España en marzo de $2005 .{ }^{56}$

Sin embargo, este clausulado fue revisado en $2006^{57}$ cuando el gobierno colombiano, después del inicio de negociaciones con Estados Unidos en el año 2004, entendió la necesidad de incorporar provisiones limitadas y detalladas en términos de inversión. Hasta entonces la experiencia de Colombia en el ámbito de negociación de tratados de inversión era limitada, si se tiene en cuenta que, salvo por el tratado con España, las últimas negociaciones colombianas se habían realizado en $1994 .{ }^{58}$ En este sentido, la revisión de 2006 incorporó actualizaciones a las normas de inversión internacionales, con la revisión de jurisprudencia del CIADI y de la UNCTAD, ${ }^{59}$ sin mayores aportes propios del Estado en función de sus intereses claros y siempre dentro del marco definido por las prácticas internacionales en la materia.

\section{ii) Modelo de negociación entre 2009 y 2011}

El modelo de negociación de 2009, producto de las actualizaciones efectuadas desde 2006, trae finalmente un modelo con definiciones y alcances establecidos. Así, en el modelo se resaltan ciertos aspectos, como las definiciones de inversionista e inversión, seguido por el ámbito de aplicación del tratado, los conceptos de trato justo y equitativo, tratamiento nacional, al igual que con las definiciones de las diferentes categorías de expropiación, las compensaciones, y finalizando con las cláusulas del medio ambiente y la solución de controversias.

Se consideran inversionistas sujetos de protección a las personas naturales con nacionalidad del país parte o a las personas jurídicas constituidas conforme a las legislaciones de los Estados partes. Pero un aspecto

\footnotetext{
56 Tratado que entró en vigor en 2007, UNCTAD, “Análisis de la política de inversión de Colombia”, Naciones Unidas, Ginebra, 2006, p. 26, en http://unctad.org/es/docs/ iteipc200511_sp.pdf

57 Ibid.

58 Colombia antes de 2005-2006 había negociado en temas de tratados de inversión (1994), dejando los años de 1995-2005 sin avances en materia de inversión extranjera.

59 UNCTAD, op. cit.
} 
por resaltar en la definición de inversionista es que Colombia agregó a la definición de persona jurídica la necesidad de que esta tenga actividades económicas sustanciales en el territorio correspondiente, para evitar situaciones de treaty shopping, que permite a filiales sin negocios reales demandar al Estado colombiano por los beneficios del tratado.

En la definición de inversión se incluyó todo tipo de activo económico que ha sido invertido de acuerdo con la ley del territorio, con un criterio muy amplio, ${ }^{60}$ y el modelo acogió la visión de posestablecimiento al determinar que las inversiones protegidas serán únicamente aquellas que se configuren después de la entrada en vigor del acuerdo.

En cuanto a aquellos actos que no constituyen inversión protegida, el modelo siguió las recomendaciones del documento Conpes 3197 del 26 de agosto de 2002, excluyendo las operaciones de deuda pública, reclamaciones originadas por contratos comerciales de compraventa de bienes y servicios por una entidad legal nacional de las partes y los créditos otorgados producto de una transacción comercial.

En cuanto a las características de la inversión, el modelo, al definir la inversión como el aporte de un capital u otro recurso, la expectativa de ganancia o beneficio y la asunción de un riesgo por parte del inversionista, adopta de cierta forma la jurisprudencia de los tribunales de arbitramento que definen qué es una inversión. ${ }^{61}$

El modelo también incluyó los conceptos desarrollados hasta el momento de trato no menos favorable y de trato justo equitativo de la normativa de comercio internacional y por la costumbre de derecho internacional. Otro punto para destacar es la inclusión de las definiciones de expropiación tanto directa como indirecta. En cuanto a la expropiación directa, se estableció que la inversión extranjera no estará sujeta a

60 Se incluyen: bienes muebles e inmuebles, así como cualquier otro derecho real, incluidos los de propiedad; acciones, partes y cualquier otro tipo de participación económica en empresas; reclamaciones dinerarias o cualquier actuación que tuviera un valor económico; derechos de propiedad intelectual, incluidos derechos de autor, conexos, de propiedad industrial, como patentes, procesos técnicos, marcas, marcas comerciales de los fabricantes, nombres comerciales, diseños industriales, conocimientos y el goodwill; concesiones otorgadas por ley, mediante acto administrativo o contrato, incluidas concesiones para explorar, extraer, explotar o cultivar recursos naturales. Todas las operaciones de préstamo externo, según lo establecido por la ley de cada parte contratante.

61 Rivas, op. cit., p. 206; el equipo formulador tuvo en cuenta la jurisprudencia de Fedax c. Venezuela y Salini Costruttori SpA y Italtrade SpA c. Marruecos. 
nacionalización, expropiación directa o indirecta, ni a ninguna medida que tuviese efectos similares, salvo por motivos de interés público o interés social, de manera no discriminatoria, de buena fe y acompañada de una compensación pronta, adecuada y efectiva. Colombia, hasta 1999, había declarado como inconstitucional todos los tratados de inversión que establecían que toda expropiación debía ser compensada, pues el artículo 58 de la Constitución Política permitía no indemnizar la expropiación en los casos que el legislador determinara. Sin embargo, el Acto Legislativo 1 de 1999 eliminó del estatuto superior tal tipo de expropiación, permitiendo entonces incluir en el ordenamiento jurídico aquellos tratados que autorizaran la indemnización en los casos de expropiación. ${ }^{62}$ En esta definición de expropiación directa se hace la distinción entre la utilidad pública y el interés social, pues, mientras que la primera se refiere a una capacidad propia que tiene la administración, el último se entiende como un fin social tutelado como tal, pero que puede y normalmente está entregado a la actividad privada. ${ }^{63}$

En lo atinente a la expropiación indirecta, el modelo incluye que será la resulta de una medida o serie de medidas de una parte que tienen un efecto equivalente a la expropiación directa sin transferencia formal de título o confiscación directa. La determinación de si una medida o serie de medidas de una parte contratante constituye una expropiación indirecta requiere una investigación caso por caso, basada en las precisas situaciones que la rodean.

Finalmente, en materia de expropiación, el modelo incluye también la equivalencia de la compensación por expropiación, que equivaldría al valor del mercado en el momento en el que se encontraba antes de que se adoptaran las medidas expropiatorias, o inmediatamente antes de que las medidas inminentes fueran de conocimiento público, lo que ocurriera primero.

El modelo de 2009 incluye una cláusula de compensación de pérdidas en caso de guerras, conflicto armado o disturbios civiles, donde el inversionista tendría derecho a restitución, indemnización o compensación;

\footnotetext{
62 Corte Constitucional de Colombia, sentencias C-1074 de 2002 y C-294 de la misma anualidad.

63 Corte Constitucional, Sentencia T-284 de 1994, magistrado ponente: Luciano Parejo. Hoy desarrollado por la Corte Constitucional en la Sentencia C-297 de 2011, magistrado ponente: Juan Carlos Henao Pérez.
} 
y la última sobre medio ambiente, donde los acuerdos no se pueden interpretar como limitantes para que no se cumpliera una medida de legislación ambiental.

A diferencia de los modelos de 2003 y de 2006, el modelo de 2009 trae algo de lo aprendido por el gobierno nacional en el curso de las negociaciones con Estados Unidos, la inclusión de las disposiciones internacionales y algunas definiciones aportadas por la jurisprudencia. Sin embargo, estos modelos son dinámicos, por lo cual sobre la base del modelo de 2009 se hicieron unas modificaciones para establecer el modelo de 2011, que sirvió como soporte en las negociaciones con Corea, Singapur, Francia y Turquía. ${ }^{64}$

Este modelo de 2011 procuró incluir aún más detalle en las definiciones y conceptos. Por ejemplo, la definición de inversión fue ampliada y los conceptos de nación más favorecida, trato nacional y trato justo y equitativo ${ }^{65}$ fueron más detallados. Este modelo de 2011 fue la consecuencia de las negociaciones de por lo menos diez de los tratados que entraron en vigor entre 2002 y 2010.

\section{iii) Modelo de negociación de $2017^{66}$}

El modelo de 2017 es la actualización del modelo de 2011, producto de la participación de la academia, de firmas de abogados con experticia en el derecho internacional de las inversiones, así como de la Conferencia de las Naciones Unidas sobre Comercio y Desarrollo y del Instituto Internacional para el Desarrollo Sostenible. ${ }^{67}$ Este nuevo modelo trae aspectos innovadores y da respuesta a ciertas problemáticas del Estado colombiano en materia

64 Estos tratados están suscritos por Colombia, pero no han sido ratificados, por lo que no han entrado en vigor. "Acuerdos internacionales suscritos", en http://www.tlc.gov.co/ publicaciones/6421/acuerdos_internacionales_de_inversion_suscritos

65 "Modelo de acuerdo de promoción y protección recíproca de inversiones 2011", en http://investmentpolicyhub.unctad.org/Download/TreatyFile/3559

66 "Modelo de acuerdo de inversiones entre la República de Colombia y... 2017”, en http: / / www.mincit.gov.co/loader.php?IServicio $=$ Documentos\&lFuncion $=$ verPdf\&id $=7$ 4882\&name=AAI_Modelo_2017.pdf\&prefijo=file

67 Ministerio de Comercio, Industria y Turismo, "Comentarios al modelo de acuerdo internacional de inversión 2017 de Colombia", en http:/ / www.mincit.gov.co/loader.php? 1 Servicio $=$ Documentos $\& l$ Funcion $=$ verPdf $\& i d=81559 \&$ name $=$ Comentarios_al_Modelo_de_Acuerdo_Internacional_de_Inversio?n_2017_de_Col...pdf\&prefijo $=$ file 
de inversiones, especialmente a las demandas a las que ha sido sometido. Como característica principal del modelo de 2017, según el Ministerio de Comercio, es que "se estructura para impedir el abuso al mecanismo ICISD (CIADI) mencionado anteriormente, sin dejar de otorgar protección a los inversionistas y las inversiones que han sido realizadas y operadas de una manera consistente con el derecho colombiano e internacional". ${ }^{68}$

El modelo de 2017 logra acotar y concretar aún más las definiciones de inversión e inversionista, incluyendo elementos subjetivos y materiales en la definición. Igualmente, concreta aún más las obligaciones en cuanto a los estándares de trato. A su vez, refuerza la cláusula de denegación de beneficios, excluyendo de la protección de los acuerdos a aquellos inversionistas que hayan incurrido en conductas graves, tales como violaciones a los derechos humanos y patrocinio a grupos armados al margen de la ley. El modelo también hace referencia a que las partes contratantes deben incluir las líneas directrices de la OCDE para las empresas multinacionales.

Como se mencionó anteriormente, el modelo nace como respuesta, y en una reacción a nuestro juicio tardía, frente a las demandas que afronta Colombia actualmente. Por lo tanto, la sección más regulada y detallada es aquella relevante a la solución de controversias del inversionista-Estado. El modelo incluyó la posibilidad de que el Estado presente pretensiones en contra del inversionista reclamante en cuanto al objeto de la disputa por conductas que ameriten la denegación de los beneficios del tratado, disposición que no era incluida en los modelos anteriores. Por otra parte, el más reciente modelo incluye dos figuras nuevas, como lo es el establecimiento de un consejo bilateral de inversión, figura análoga a la establecida en los consejos administradores de los tratados de libre comercio, que reúne las funciones de supervisar la aplicación del acuerdo suscrito. Por su parte, la segunda figura permite la posibilidad de que las partes contratantes en su derecho interno establezcan una figura del defensor del inversionista con funciones de facilitación de la inversión para prevenir el uso del CIADI.

El enfoque del Estado en la creación del modelo de 2017 no es la actualización de las definiciones de inversionista, o de inversión, si bien se extienden y se detallan más con la creación de cada nuevo modelo, sino la de prevenir en la mayor medida posible que los conflictos de inversionistaEstado lleguen a instancias internacionales. Por eso, se incluyen figuras como el consejo de inversión o el defensor del inversionista.

68 Ibid. 
De las características recopiladas del modelo en referencia cabe el siguiente análisis. Como se abordó supra, el más reciente modelo de acuerdo internacional de inversión diseñado por el Ministerio de Comercio, Industria y Turismo contiene disposiciones que procuran que el instrumento sea claro, por un lado, y, por el otro, pretende reducir la ambivalencia en la interpretación que, generalmente, es motivo de controversia entre las partes contratantes.

Valga aclarar que el modelo de acuerdo, atendiendo a las precisas exigencias del comercio internacional, tanto como a las necesidades en el orden doméstico, propendió por un equilibrio conducente al fomento de la cooperación económica, la prosperidad y el desarrollo sostenible, en armonía con la preservación de la facultad soberana del Estado para regular asuntos de interés público y proteger objetivos legítimos (v.g., salud, orden público, derechos laborales, medio ambiente).

Sin duda, este modelo se alimenta de las experiencias de Estados de la región 'vapuleados' económicamente por cuantiosas demandas que han prosperado, así como por la evidencia de que los instrumentos internacionales de inversión terminan maniatando al Estado, a tal punto de desatender el cumplimiento de sus fines e inobservar las actuaciones tendientes a la prevalencia del interés general. Así, es dable aseverar que el modelo limita los efectos frente a la enajenación de la soberanía estatal, así como la posibilidad de presentar reclamaciones infundadas o cuya causa generadora resida en asuntos circunscritos a la órbita regulatoria del Estado. Como se insistió, el modelo no procura renunciar a la pretendida inserción en la economía global y aumento de la inversión extranjera directa, sino tratar de armonizar dicho fin con los derroteros de la política nacional y el desarrollo sostenible.

Los cambios incorporados en el documento contentivo del modelo de acuerdo de inversiones diseñado para Colombia son importantes. Tanto es así que el anexo 2 - "Presentación de un reclamo ante una corte o tribunal" - previó cláusulas relativas a la posibilidad de que la parte demandada presente pretensiones reconvencionales en contra del inversionista demandante. Aunque se sostenga que dicho escenario, en sede del arbitraje de inversión, es inoperante, dos son los precedentes que habilitarían la incorporación de estas disposiciones en el texto de un acuerdo internacional de inversión: 1) Urbaser S.A. y Consorcio de Aguas 


\section{Bilbao Bizkeaia c. la República de Argentina ${ }^{69}$ y 2) Burlington Resources Inc. c. la República del Ecuador. ${ }^{70}$}

69 La disputa sometida al Centro Internacional de Arreglo de Diferencias Relativas a Inversiones (CIADI) versa sobre una concesión de servicio de aguas y cloacas por ser provista en el Gran Buenos Aires. i) El adjudicatario de la mentada concesión fue una empresa constituida por inversionistas extranjeros —Aguas del Gran Buenos Aires S.A. (AGBA)—, que, en sus términos, habrían padecido los múltiples escollos impuestos por las autoridades provinciales que imposibilitaron la operación continua y eficiente de la concesión. Con ocasión a la referida rescisión, el inversionista presentó su reclamación basado en el acuerdo suscrito con el Reino de España, en particular el artículo $3^{\circ}$, que impone la obligación de protección de las inversiones extranjeras y prohíbe la adopción de medidas injustificadas o discriminatorias; el artículo $4^{\circ}$, que consagra el estándar de trato justo y equitativo; y el artículo $5^{\circ}$, que prohíbe la expropiación ilícita y discriminatoria de las inversiones extranjeras. $Y$ ii) el rechazo en su integridad de la demanda reconvencional presentada por Argentina. Por su parte, la demandada solicitó al tribunal, tanto en el memorial de contestación como en el de dúplica, que rechazara las pretensiones de la demandante y, de especial interés para el análisis, que diera lugar a la demanda reconvencional de Argentina y, en consecuencia, le otorgara una indemnización más intereses anteriores y posteriores al laudo desde que se ocasionaron los daños y hasta la fecha efectiva del pago. A juicio del Estado demandado, las dificultades que sobrevinieron al contrato de concesión son imputables a la gestión deficiente de la AGBA y sus accionistas, dada la incapacidad de regularizar la cobranza a los usuarios de la red. A su vez, la afectación obedeció a la desatención de los deberes de los inversionistas, comoquiera que se evidenció que no se desplegaron las inversiones mínimas requeridas para los primeros años de la concesión, lo que implicó, de suyo, la incapacidad de cumplir los compromisos derivados de la expansión de la red. Esa dificultad se tradujo en lo que el Estado consideró configuraba responsabilidad internacional de la empresa concesionaria por violaciones al derecho humano al agua. El caso de la referencia constituye un hito en los arbitrajes de inversión, toda vez que demostró que el CIADI puede declararse con jurisdicción para conocer de una demanda reconvencional en la que el Estado demandado planteó la responsabilidad de la concesionaria por violación del derecho humano al agua. La asunción de competencia se fundó en las siguientes consideraciones: la legitimación del Estado para elevar la reclamación en sede arbitral, por así disponerlo el instrumento de inversión; y el reconocimiento del derecho internacional general como norma aplicable al asunto - lo que supone el aparejamiento y/o armonización del derecho de las inversiones con el derecho internacional público- - Urbaser S.A. and Consorcio de Aguas Bilbao Biqkeaia, Bilbao Biskaia Ur Partzuergoa v. The Argentine Republic, ICSID Case $\mathrm{ARB} / 07 / 26$.

70 Este segundo asunto reprodujo un escenario similar al ya abordado, correspondiente al análisis de los principios y reglas del derecho de las inversiones en armonía con las obligaciones que subyacen al derecho internacional, con especial atención en el derecho medioambiental. Así mismo, comprende la habilitación del Estado para reclamar por los daños ocasionados por el inversionista a bienes colectivos, pretensiones que se fundan en un cúmulo de fuentes de derecho internacional que las respaldan y robustecen. Bajo la égida del Tratado Bilateral de Inversión entre Estados Unidos y Ecuador, Burlington 
El modelo de 2017 responde de manera más concreta a varios de los reparos realizados a lo largo de este escrito en cuanto a las dificultades surgidas de la previsión de estándares de protección amplios para los inversionistas, con definiciones sujetas a diversas interpretaciones por parte de los tribunales arbitrales de carácter internacional. Aún queda un camino largo por recorrer en cuanto a la evaluación de la conveniencia de continuar negociando, suscribiendo y ratificando APPI, y en cuanto a los riesgos que representa para la capacidad regulatoria del Estado no solo la incorporación de las protecciones tradicionalmente reconocidas, sino entregar la solución de controversias a instancias internacionales, particularmente al CIADI, cuya legitimidad está hoy en cuestión como consecuencia

inició el arbitraje el 21 de abril de 2008 como consecuencia de la modificación de su participación como contratista del Estado en los contratos de exploración y explotación de los bloques 7 y 21 de la región Amazónica. Esa modificación unilateral, que comprendió medidas tributarias dirigidas a las empresas petroleras, aunado a la toma de posesión de los activos de la compañía, derivó en una supuesta expropiación de los bloques petroleros que operaban en territorio ecuatoriano. En escrito contentivo de la demanda fechado de abril de 2009, y en memorial suplementario de 2010, Burlington solicitó que se declarara el incumplimiento de las obligaciones respecto de las inversiones de la empresa y particularmente la prohibición de expropiación sin indemnización. En línea con el caso anterior, Ecuador presentó dos contrademandas argumentado para el efecto que la empresa era responsable de los daños medioambientales causados en áreas situadas en los bloques 7 y 21 de la región Amazónica —esto es, la desatención a los deberes y obligaciones de carácter medioambiental—, y por los costes incurridos por el Estado para remediar las condiciones deficientes de infraestructura — desconociendo con ello la obligación de devolver la infraestructura en buenas condiciones de funcionamiento-. Cabe precisar que en decisión proferida por el tribunal se sostuvo que la medida de orden tributario, aunque modificatoria del equilibrio económico del contrato, no tuvo efectos expropiatorios para la compañía, en tanto que no la privó de su inversión en el Estado ecuatoriano. Además, el tribunal reconoció la potestad soberana de los Estados para imponer impuestos tanto a nacionales como a extranjeros que efectuaran inversiones en el país receptor. Siendo así, la imposición de un tributo resulta del ejercicio del poder regulatorio del Estado y no comporta una expropiación. La expropiación violatoria del acuerdo de inversión que entendió configurada obedeció a la operación asumida de los bloques 7 y 21 no habiendo concurrido los supuestos conducentes a la declaratoria de caducidad del contrato. En últimas, Ecuador fue condenado a pagar la suma de 379 millones de dólares por la expropiación indirecta a la que hubo lugar. Empero, en el laudo se concluyó que el inversionista también era responsable por los daños medioambientales causados en territorio ecuatoriano, por lo que la condenó a la no despreciable suma de 41 millones de dólares. Procuraduría General del Estado, Burlington Resources Inc. c. la República del Ecuador (ARB/08/05 CIADI), 2017, en www.pge.gob.ec/images/2017/casos/burlington/BLOG/ANTECEDENTES_BURLINGTON_RESOURCES_INC_5.0.pdfdad 
precisamente de la disparidad de conceptos en las decisiones; la falta de transparencia; la existencia de un 'club' informal de árbitros concentrados en los países desarrollados que también fungen como abogados, dejando dudas sobre su imparcialidad; y los altos costos en que se incurre para acudir a esta instancia, entre otros. ${ }^{71}$

\section{Conclusiones}

La postura de los últimos gobiernos ha sido la de impulsar y desarrollar la inversión extranjera directa (IED) en el país, como generadora de desarrollo, inversión que en la práctica ha estado altamente centrada en actividades extractivas, sin que el país haya logrado consolidar un marco normativo estable e integral para la regulación del ingreso de la inversión extranjera destinada a actividades que históricamente han sido relevantes para la economía colombiana.

Durante estos 17 años los gobiernos nacionales han tratado de encontrar en la inversión extranjera la base para el desarrollo de la industria y la economía del país, y en tal sentido los últimos dos presidentes han profundizado las políticas para la garantía de la protección y para el establecimiento de reglas que alentaran la inversión, así como para el establecimiento de prerrogativas que fueran el fundamento principal para la atracción de capitales, sin que pueda decirse que estas políticas hayan estado acompañadas de una mirada integral y estructurada de los beneficios, y sobre todo de los eventuales riesgos de la inversión extranjera para ciertos sectores, al igual que para la capacidad regulatoria del Estado en temas como los derechos humanos, la protección del medio ambiente, las medidas contra la corrupción.

El centro de la política de inversión se ha situado en la celebración de acuerdos internacionales para la protección y promoción de las inversiones, en el entendido de que estos son los mecanismos más convenientes para la proyección del país en diferentes mercados mundiales, especialmente con socios comerciales, que al pertenecer a las economías más desarrolladas podrían ver un valor agregado en estos acuerdos y apreciar las facilidades

71 García Bolívar, Ómar E., "La crisis del derecho internacional de inversiones extranjeras: propuestas de reforma", Revista de la Secretaría del Tribunal Permanente de Revisión, 2015, 3, (5), pp. 137-163. 
necesarias para el ingreso de productos, bienes y servicios nacionales en diferentes latitudes del mundo.

Como consecuencia de las políticas definidas a lo largo de los últimos años, de la experiencia en los procesos de negociación y de la aplicación de los acuerdos suscritos, el Estado ha procurado construir distintos modelos, todos los cuales han respondido a las directrices internacionales en la materia, de manera que se han incorporado de modo más o menos conservador los estándares tradicionales de protección, y por esa razón es factible que en los procesos de negociación se haya logrado conservar una buena parte del modelo o ceder sin mayor resistencia a las demandas de los otros Estados en los procesos de negociación, en aspectos como la inclusión de las cláusulas paraguas, la mayor amplitud del concepto de trato justo y equitativo o del trato nacional.

Solo hasta el modelo de 2017, cuando el país ya se vio abocado a varias demandas ante el CIADI, las instancias competentes se preocuparon por proponer un modelo de APPI que contribuya a blindar al país en contra de futuras demandas ante instancias internacionales, en la medida en que en el escenario internacional Colombia actualmente se enfrenta a cinco demandas, tres de las cuales están bajo la jurisdicción del CIADI $^{72}$ y dos bajo la Comisión de las Naciones Unidas para el Desarrollo Mercantil Internacional. ${ }^{73} \mathrm{El}$ modelo de 2017 pretende entonces de cierta forma solucionar algunos de los errores cometidos en los textos anteriores, que fueron la base de las demandas por problemas de falta de claridad y detalle. Así mismo, se pretende por medio de un clausulado más extenso evitar el abuso del mecanismo de solución de controversias, evitando también futuras demandas.

Sin duda siguen en discusión, tanto en el ámbito interno como en el internacional, las reales bondades de la suscripción de tratados que protejan a los inversionistas, sin que existan, de una parte, políticas claras de parte del Estado en las cuales se fijen las prioridades de admisión de la inversión extranjera, los sectores limitados a esta y las salvaguardas en términos de protección de la capacidad regulatoria de los Estados; y, de otra parte, un análisis concienzudo de los riesgos jurídicos, económicos y políticos de

\footnotetext{
72 Ante el CIADI se encuentran los procedimientos América Móvil v. Colombia, ICSID Case ARB(AF)/16/5); Eco Oro Minerals Corp. c. Colombia, ICSID Case ARB/16/41; Glencore International A. G. and C. I. Prodeco S.A. c. Colombia, ICSID Case ARB/16/6.

73 Entre esos está Cosigo Resources and others v. Colombia y Gas Natural Fenosa (Electricaribe) c. Colombia.
} 
permitir que los inversionistas acudan a instancias internacionales como el CIADI, cuya legitimidad hoy está en discusión.

\section{Referencias}

\section{Artículos académicos}

Castro Peña, M. N., "El Estado colombiano ante un arbitraje internacional de inversión”, Derecho del Estado, 2017, (38), pp. 23-66.

Gamboa Morales, Nicolás, "Algunas consideraciones sobre antecedentes y evaluación arbitral de la cláusula paraguas", Revista Brasileira de Arbitragem, 2009, 5, (22), pp. 116-129.

García Bolívar, Ómar E., "La crisis del derecho internacional de inversiones extranjeras: propuestas de reforma", Revista de la Secretaría del Tribunal Permanente de Revisión, 2015, 3, (5), pp. 137-163.

Illescas, J., "Los tratados de protección de inversiones y su utilidad para los inversores españoles en Latinoamérica", Actualidad Jurídica Uría \& Menéndez, 2003, (5), pp. 83-94.

Linares Cantillo, Alejandro, "La reforma al artículo 58 de la Carta. Internacionalizar la protección: una forma de estimular la inversión extranjera", Ámbito Jurídico, 2000, 2, (8).

Márquez Escobar, Pablo \& Villegas, Lorenzo, "Regulación e inversión extranjera: los tratados de promoción recíproca de inversiones y el estándar de trato justo y equitativo", Revista Colombiana de Derecho Internacional, 2009, 7, (15) edición especial, pp. 155-180.

Moyano Buitrago, M. L. \& Gil León, J. M., "Efectos de la inversión extranjera directa sobre el crecimiento económico en Colombia: evidencia empírica 2000-2010", Apuntes del CENES, 2015, 34, (59), pp. 63-92.

Páez, M., "La expropiación indirecta frente al CIADI: consideraciones para la autorregulación de los actos administrativos de los Estados", Revista de Estudios Internacionales, 2006, 39, (153), pp. 5-36.

Salacuse, J. W., The law of investment treaties, Oxford University Press, Nueva York, 2010.

Schlemmer, Engela C., "An overview of South Africa's bilateral investment treaties and investment policy", ICSID Review - Foreign Investment Law Journal, 2016, 31, (1), pp. 167-193.

Sommer, Cristian, "La aplicación de estándares de protección de inversiones extranjeras. Una mirada desde los casos argentinos", Anuario Colombiano de Derecho Internacional, 2013, 6, pp. 95-130. 
Vandevelde, K., "The Bilateral Investment Treaty Program of the United States", Cornell International Law Journal, 1988, 21, pp. 201-276.

Yackee, J., "Bilateral investment treaties, credible commitment, and the rule of (international) law: do BITs promote foreign direct investment?", Law \& Society Review, 2008, 42, (4), p. 806.

\section{Libros}

Brown, Chester \& Devashish, Krishan (eds.), Commentaries on selected model investment treaties, Oxford University Press, 2013.

Méndez, C. F., "Tratamiento de la inversión extranjera en Colombia", en García Matamoros, L. \& Aljure Salame, A. C., Estudios contemporáneos de derecho internacional privado, Universidad del Rosario-Legis, Bogotá, 2016.

\section{Documentos electrónicos}

“Uribe, 8 años en el poder. 2002-2010”, ElTiempo, 17 de diciembre de 2010, en http:/ / www.eltiempo.com/archivo/documento/MAM-4332319

Bernasconi-Osterwalder, Natalie \& Dietrich Brauch, Martín, "Comparative commentary to Brazil's cooperation and investment facilitation agreements (CIFAs) with Mozambique, Angola, Mexico, and Malawi”, en https:/ / www.iisd.org/library/comparative-commentary-brazilcooperation-and-investment-facilitation-agreements-cifas

Colombia, Ministerio de Comercio, Industria y Turismo, "Acuerdos internacionales vigentes", en http://www.tlc.gov.co/loader.php?IServic io=Publicaciones\&id $=11963$

Guerra Bello, Gustavo, "La propuesta de modelo de acuerdo de comercio para el desarrollo del gobierno de Ecuador en materia de inversiones y comercio transfronterizo de servicios: límites y dilemas", Universidad Andina Simón Bolívar, sede Ecuador, informe de investigación, Quito, 2012, en http:/ / repositorio.uasb.edu.ec/bitstream/10644/4063/1/PI-2012-13-Guerra-La\%20propuesta.pdf

ICSID Statistics 2018-II, en https:/ /icsid.worldbank.org/en/Documents/ resources/ICSID $\% 20 \mathrm{Web} \% 20$ Stats $\% 202018-2 \% 20$ (English).pdf

OCED, en https://www.oecd.org/investment/internationalinvestmentagreements/WP-2004_1.pdf 
Randall, Williams, "Nothing sacred: developing countries and the future of international investment treaties", Department of Trade and Industry, Republic of South Africa, 2009.

UNCTAD, "Análisis de la política de inversión de Colombia", Naciones Unidas, Ginebra, 2006, en http://unctad.org/es/docs/iteipc200511_sp.pdf

Zerda Sarmiento, Álvaro, "Colombia: del Japón de Suramérica a la confianza inversionista. Dos estrategias para un patrón de crecimiento reprimarizante con iniquidad", Universidad Nacional, Facultad de Ciencias Económicas, Serie Documentos, Escuela de Economía, $\mathrm{N}^{\circ} 24$.

\section{Normas}

Colombia, Congreso de la República, Ley 1151 de 2007, Plan Nacional de Desarrollo 2006-2010.

Colombia, Congreso de la República, Ley 152 de 1994.

Colombia, Congreso de la República, Ley 19 de 1958.

Colombia, Congreso de la República, Ley 790 de 2002.

Colombia, Congreso de la República, Ley 812 de 2003, Plan Nacional de Desarrollo 2002-2006.

Colombia, Consejo Nacional de Política Económica y Social, Departamento Nacional de Planeación, Documento Conpes 3429 del 13 de junio de 2006, modificación al régimen de inversión extranjera en Colombia, en https://colaboracion.dnp.gov.co/CDT/Conpes/ Econ\%C3\%B3micos/3429.pdf

Colombia, Consejo Nacional de Política Económica y Social, Departamento Nacional de Planeación, Documento Conpes 3197 de 2002, relativo al manejo de flujos de endeudamiento, en https://colaboracion.dnp.gov.co/CDT/Conpes/Econ\%C3\%B3micos/3197.pdf

Colombia, Consejo Nacional de Política Económica y Social, Departamento Nacional de Planeación, Documento Conpes 3221 de 2003, ajustes a la normatividad de la inversión extranjera, en https://colaboracion.dnp.gov.co/CDT/Conpes/Econ\%C3\%B3micos/3221.pdf

Colombia, Consejo Nacional de Política Económica y Social, Departamento Nacional de Planeación, Documento Conpes 3684 del 19 de octubre de 2010, fortalecimiento de la estrategia del Estado para la prevención y atención de controversias internacionales de inversión, en http://www.nuevalegislacion.com/files/susc/cdj/ conc/conpes_3684.pdf 
Colombia, Consejo Superior de Comercio Exterior, Sesión 89, "Agenda de negociaciones comerciales de Colombia: actualización 2011”, en http://www.mincit.gov.co/loader.php?1Servicio=Documentos \&lFuncion=verPdf\&id=52\&name=Agenda_negociaciones_2011. pdf\&prefijo $=$ file

Colombia, Presidencia de la República, Decreto 1866 de 2005.

Colombia, Presidencia de la República, Decreto 1888 de 2008, por el cual se modifica el Régimen General de Inversiones de Capital del Exterior en Colombia y de Capital Colombiano en el Exterior.

Colombia, Presidencia de la República, Decreto 2080 de 2000, modificado parcialmente por los decretos, en http://www.mincit.gov.co/publicaciones/14832/normatividad_sobre_inversion_extranjera1844

Colombia, Presidencia de la República, Decreto 2466 de 2007, por el cual se modifica el Régimen General de Inversiones de Capital del Exterior en Colombia y de Capital Colombiano en el Exterior.

Colombia, Presidencia de la República, Decreto 2553 de 1999.

Colombia, Presidencia de la República, Decreto 4085 de 2011.

Colombia, Presidencia de la República, Decreto 4210 de 2004.

\section{Decisiones}

América Móvil v. Colombia, ICSID Case ARB(AF)/16/5).

Burlington Resources Inc. v. Republic of Ecuador, ICSID Case ARB/08/5.

Colombia, Corte Constitucional, Sentencia C-1074 de 2002, magistrado ponente: Manuel José Cepeda Espinosa.

Colombia, Corte Constitucional, Sentencia C-294 de 2002, magistrado ponente: Jaime Araújo Rentería.

Colombia, Corte Constitucional, Sentencia C-297 de 2011, magistrado ponente: Juan Carlos Henao Pérez.

Colombia, Corte Constitucional, Sentencia T-284 de 1994, magistrado ponente: Luciano Parejo.

Eco Oro Minerals Corp. c. Colombia, ICSID Case ARB/16/41.

El Paso Energy International Company c. República de Argentina, CIADI Caso ARB/03/15, decisión de jurisdicción del 17 de abril de 2006.

Enron Corporation and Ponderosa Assets LP c. República de Argentina, CIADI Caso ARB/01/3, decisión de jurisdicción del 13 de enero de 2004.

Glencore International A. G. and C. I. Prodeco S.A. c. Colombia, ICSID Case $\mathrm{ARB} / 16 / 6$. 
Técnicas Medioambientales Tecmed, S.A. v. The United Mexican States, ICSID Case $\mathrm{ARB}(\mathrm{AF}) / 00 / 2$.

Urbaser S.A. and Consorcio de Agnas Bilbao Bizkaia, Bilbao Biskaia Ur Partzuergoa v. The Argentine Republic, ICSID Case ARB/07/26.

Waste Management, Inc. v. United Mexican States (Number 2), ICSID Case $\mathrm{ARB}(\mathrm{AF}) / 00 / 3$.

\section{Modelos}

"Modelo de acuerdo de inversiones entre la República de Colombia y... 2017", en http:/ /www.mincit.gov.co/loader.php?1Servicio=Docu mentos\&lFuncion=verPdf\&id=74882\&name=AAI_Modelo_2017. pdf\&prefijo $=$ file

"Modelo de acuerdo de promoción y protección recíproca de inversiones 2011", en http://investmentpolicyhub.unctad.org/Download/ TreatyFile/3559

Colombia, Ministerio de Comercio, Industria y Turismo, "Comentarios al modelo de acuerdo internacional de inversión 2017 de Colombia", en http://www.mincit.gov.co/loader.php?1Servicio=Docum entos\&lFuncion=verPdf\&id $=81559 \&$ name $=$ Comentarios_al_Modelo_de_Acuerdo_Internacional_de_Inversio?n_2017_de_Col.... pdf\&prefijo $=$ file 